Recepción: 20 / 02 / 2019

Aceptación: 19 / 03 / 2019

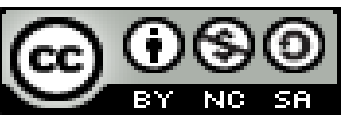

Ciencias económicas y empresariales

Publicación: 05 / 05 / 2019

Artículo de investigación

\title{
Diagnóstico de responsabilidad social empresarial de las pymes procesadoras de lácteo, en el Cantón Cañar
}

\section{Diagnosis of corporate social responsibility of SMEs processing dairy, in el Cañar Canton}

Diagnóstico de responsabilidade social das PME, processamento de leite, em el Cañar Cantão

\author{
Silvio Eduardo Angamarca-Calderón ${ }^{\mathrm{I}}$ \\ sangamarcac@yahoo.com \\ Cristina Guadalupe Ordoñez-Espinoza II \\ crisguad@hotmail.com \\ Mariory Priscila Orbe-Guaraca ${ }^{\text {III }}$ \\ Mporbeg_572@hotmail.com
}

Correspondencia: sangamarcac@yahoo.com

\footnotetext{
I. Magíster en Gestión Empresarial, Economista, Universidad Católica de Cuenca, Cuenca, Ecuador.

II. Magíster en Gestión Empresarial, Ingeniero Empresarial, Universidad Católica de Cuenca, Cuenca, Ecuador.

III. Magister en Gestión Empresarial, Ingeniero Empresarial, Universidad Católica de Cuenca, Cuenca, Ecuador.
} 


\title{
Resumen
}

El presente trabajo de investigación tiene como objetivo fundamental realizar un diagnóstico de las prácticas que se emplean para el cumplimiento de la Responsabilidad Social Empresarial (RSE) de las Pequeñas y Medianas Empresas (PYMES) en procesadoras de lácteos en el cantón Cañar, que permitan la elaboración de los respectivos planes de RSE y su correspondiente aplicación en beneficio de su desarrollo. Para la realización de este diagnóstico, se consideró el cuestionario propuesto por ETHOS como una herramienta de evaluación y aprendizaje de las empresas en materia de RSE. El cuestionario fue aplicado a las 4 empresas procesadoras de lácteos existentes en el cantón Cañar. Se pudo concluir que la implementación de prácticas de RSE dentro de las PYMES permite construir una estrategia integral, enfocada en sus grupos de intereses mediante el reconocimiento de sus acciones, lo cual repercute positivamente en las utilidades de la empresa, la ventaja competitiva y el posicionamiento en el mercado en búsqueda de la sostenibilidad de la misma.

Palabras claves: Empresarial; lácteos; social; responsabilidad; PYMES.

\begin{abstract}
The main objective of this research work is to carry out a diagnosis of the practices used for the fulfillment of the Corporate Social Responsibility (CSR) of Small and Medium Enterprises (SMES) processing dairy products in the canton Cañar, which allow the elaboration of the respective CSR plans and their corresponding application for the benefit of their development. To carry out this diagnosis, the questionnaire proposed by ETHOS was considered as a tool for evaluation and learning of companies in the field of CSR. The questionnaire was applied to the 4 dairy processing companies in the canton of Cañar. It was concluded that the implementation of practices of CSR in SMEs allows to build an integral strategy, focused on groups of interests through the recognition of their actions, which has a positive impact on profits of the company, the competitive advantage and positioning in the market in pursuit of the sustainability of the same.
\end{abstract}

Keys words: Business; dairy products; Social; responsibility; SMEs 


\section{Resumo}

O principal objetivo deste trabalho de pesquisa é realizar um diagnóstico das práticas utilizadas para cumprir com a Responsabilidade Social Corporativa (RSC) das Pequenas e Médias Empresas (PMEs) em processadores de lácteos no cantão de Cañar, que permitem preparação dos respectivos planos de RSC e respectiva candidatura em benefício do seu desenvolvimento. Para realizar esse diagnóstico, o questionário proposto pelo ETHOS foi considerado como uma ferramenta de avaliação e aprendizagem para empresas no campo da RSE. O questionário foi aplicado às 4 empresas processadoras de laticínios do cantão de Cañar. Concluiu-se que a implementação de práticas de RSE dentro das PMEs permite a construção de uma estratégia integral, focada em seus grupos de interesse através do reconhecimento de suas ações, o que tem um efeito positivo nos lucros da empresa, vantagem competitiva e posicionamento no mercado em busca da sustentabilidade do mesmo.

Palavras chaves: Negócios; laticínios; social responsabilidade; PMEs

\section{Introducción}

Los antecedentes de Responsabilidad Social Empresarial (RSE) se ubican desde inicios del siglo XX en Estados Unidos, relacionando esta responsabilidad con la filantropía y la caridad; en los años 90 la Comisión Europea amplía el concepto considerando también la ética y la moral, los propietarios encaminan sus acciones favoreciendo a los trabajadores, reivindicando derechos laborales y las desigualdades generadas en la sociedad. En los inicios del siglo XXI se amplía hacia los grupos de interés y su integración social, el medio ambiente y el desarrollo sustentable y humano (Viteri, 2010). En líneas generales, lo que aborda la responsabilidad social empresarial es el aporte que una organización le devuelve a la sociedad en contraprestación por ejercer una actividad económica, en muchos casos es más exigida en las empresas que por su actividad tienden a dañar el medio ambiente, generando por parte del Estado la subvención o reducción de impuestos por la preservación del medio ambiente visto esto como una acción responsable.

La responsabilidad social de las empresas comenzó a formalizarse desde los inicios del siglo XX y se han ido generando varios aportes hasta llegar a la Responsabilidad Social Empresarial (RSE), conocimiento considerado en la actualidad como una herramienta estratégica que genera ventajas competitivas en las organizaciones, permitiéndoles su crecimiento y desarrollo empresarial y por lo tanto su permanencia en el mercado altamente competitivo y cambiante de la actualidad (Viteri, 2010). 
En muchos países se generan condiciones muy favorables a las empresas, la razón principal es que se genere una conexión más profunda de la empresa con la sociedad y que no solo sea vista como una relación puramente comercial (Consumidor - productor), no solo en la protección del medio ambiente, sino aportes a las clases más desprotegidas, acciones sociales, entre otras.

De acuerdo a Torres (2014), la norma ISO 26000 manifiesta que "La responsabilidad social empresarial (RSE), es una nueva forma de hacer empresa, que se vincula al proceso de globalización de la economía mundial, surge del convencimiento de la necesidad de innovación empresarial para la competitividad y la sustentabilidad del negocio, debe ir más allá de lo puramente tecnológico para instalarse definitivamente en el ámbito de la gestión y de la relación de la empresa con su entorno social y medio ambiental y particularmente, en el espacio de lo laboral” (p. 2). En este aspecto lo social también es visto como las contribuciones no económicas que la organización aporta a los trabajadores, en muchos casos se estimula una relación más profunda empleador - trabajador, por medio de planes vacacionales, fiestas de fin de año, premios a los mejores trabajadores.

Aunque parece que la RSE se aplica solamente a las grandes empresas, su utilización en las PYMES se considera fundamental para que estas puedan desarrollar competitividad, porque permite el mejoramiento de sus productos o servicios, generando fidelidad del trabajador y del cliente, favorece el desarrollo de su imagen y reputación organizacional que conlleva a una mayor interrelación con sus socios empresariales, obtiene una mejor posición en el mercado, genera una reducción de costos y por lo tanto un incremento de sus ganancias.

En América Latina las aplicaciones de RSE comienzan a tener su importancia, aunque con diversidad dependiendo de cada país, no existe una normativa regional al respecto, por lo tanto, se encuentran rezagadas en términos de RSE con relación a Norte América y Europa. No obstante, a partir de los años 90 se han generado organizaciones de mucha importancia como ETHOS en Brasil, la Asociación Empresarial para el Desarrollo (AED) de Costa Rica, Responsabilidad Social Empresarial del Pacto Mundial de las Naciones Unidas, ISO 26000.

Las PYMES en América Latina relacionan sus prácticas de RSE con la generación de empleo, productos de calidad, capacitación de empleados, ahorro de agua y energía, disminución de desechos, cumplimento de la ley, entre otros, así como también la consideración de grupos de interés y la creación de un valor mezclado (valor económico, valor social y valor ambiental). 
El camino relacionado con la información social y ambiental en Brasil tiene una trayectoria larga que se vincula al Instituto Ethos, que fue creado en 1998 por iniciativa de un grupo de empresarios brasileños tomando como fuente de inspiración a la institución norteamericana Business and Social Responsibility. Tiene como misión ayudar a comprender e incorporar el concepto de RSE en las políticas y prácticas empresariales sobre la base de criterios éticos, para lo cual viene desarrollando, desde 2000, indicadores de autodiagnóstico y planificación de acciones de RSE. En 2004 se creó UniEthos, una entidad sin fines de lucro independiente del Instituto Ethos pero complementaria en sus objetivos para realizar investigaciones y brindar capacitaciones a empresas (Rodríguez de Ramírez, 2013, pp. 15-16).

De acuerdo a Raufflet, Lozano, Barrera y García de la Torre (2012) argumentan que

"Los inductores fundamentales de la RSE en las PYMES son la personalidad, los valores obre la relación de su empresa con los diferentes grupos de interés, así como sobre cómo debe crear y transferir valor en conjunto. Esta especificidad toma la RSE que se practica en la PYMES en una actividad informal, esporádica, implícita, no planificada”. (p. 197)

El Ecuador se acoge a la resolución de la Comunidad Andina (CAN) dada el 21 de agosto de 2009, ratificada por el Instituto Nacional de Estadísticas y Censos (INEC) y la Superintendencia de Compañías y Valores, de acuerdo a ello las empresas se clasifican según el número de trabajadores o el valor de sus ventas. En el primer caso: microempresas (1 - 9 trabajadores), pequeña empresa (10 49 trabajadores), mediana empresa (50 - 199 trabajadores), y en el segundo caso se clasifica como microempresa (de $1 \$--100.000 \$$ en ventas anuales), pequeña empresa (100.001\$ - 1'000.000), mediana empresa (1'000.001\$ - 5’000.000\$) (Araque, 2015, p.64).

Tanto en Ecuador como en Latino América, las aplicaciones de Responsabilidad Social son nuevas y están enfocadas a una interrelación de todos los actores sociales para colaborar reflexivamente por una sociedad más justa y equitativa.

A partir de 1998 en nuestro país, existe una importante preocupación por incorporar en las empresas principios éticos y morales orientados al desarrollo de la sociedad, creándose importantes organizaciones que lideran este proceso como el Consorcio Ecuatoriano para la Responsabilidad Social (CERES), el Instituto de Responsabilidad Social Empresarial (IRSE), que promueven la RSE 
en las empresas para una sociedad sostenible y justa, entre otras. Sin embargo, nos hace falta una mayor profundidad para alcanzar estándares regionales o mundiales.

La presente investigación pretende realizar un diagnóstico de las prácticas que se realizan para el cumplimiento de la Responsabilidad Social Empresarial de las PYMES procesadoras de lácteos en el cantón Cañar, con la finalidad de socializar los resultados a las PYMES involucradas que permita la elaboración de los respectivos planes de RSE y su correspondiente aplicación en beneficio de su desarrollo.

\section{Metodología}

Para la realización del diagnóstico de Responsabilidad social Empresarial de las PYMES procesadoras de lácteos en el Cantón Cañar, se consideró el cuestionario propuesto por ETHOS como una herramienta de evaluación y aprendizaje de las empresas en materia de RSE.

\section{Indicadores Ethos.}

El Instituto se fundó en Brasil en 1998 con el objeto de desarrollar actividades en torno a la problemática de Responsabilidad Social. Ha diseñado una herramienta de aprendizaje y evaluación de la gestión de las empresas, que evalúa la incorporación de prácticas de responsabilidad social empresarial, la planificación de estrategias y el monitoreo del desempeño general de la empresa. Se trata de un instrumento de autoevaluación y aprendizaje (Viola \& Sepliarsky, 2012, p. 4).

El dictamen de Ethos está enfocado en siete temas: Valores, Transparencia y Gobierno Corporativo; Público interno; Medio ambiente; Proveedores; Consumidores y clientes; Comunidad; y, Gobierno y Sociedad. Cada tema, está dividido en un conjunto de indicadores elaborados para mostrar cómo puede la compañía mejorar su desempeño en cada aspecto (Guzmán, Gutiérrez, \& Castro, 2014, p. 215).

El dictamen del Ethos, constituye un mecanismo de inspección, vigilancia y control de las actividades de las empresas privadas. En esencia, se aspira introducir en la lógica de las empresas privadas criterios éticos que las sensibilicen sobre los efectos negativos derivados de su búsqueda obsesiva de utilidades, es decir, se pretende que las empresas incorporen en sus procesos de toma de decisión criterios diferentes al económico, tales como, el deterioro ambiental o las crisis de orden social. Este 
mecanismo consiste, en un proceso de auditoría orientado a evaluar criterios éticos y de responsabilidad social (Guzmán, Gutiérrez, \& Castro, 2014, p. 211).

Los criterios de evaluación de Ethos, según Guzmán, Gutiérrez, \& Castro (2014) son: 1) Definir cuáles serán los criterios que se van a evaluar para determinar hasta qué punto la empresa tiene una conducta ética y socialmente responsable o no. 2) Diseñar los instrumentos que se van a utilizar para evaluar esos criterios. 3) Precisar cómo se van a presentar los resultados de esta evaluación. En este caso, se emplearán dos herramientas el "Índice de Ética Empresarial" y el "Informe del Auditor" (p. 212).

Tabla 1.

Criterios de Evaluación

\begin{tabular}{|c|c|c|c|}
\hline \multicolumn{4}{|c|}{ Criterios de Evaluación } \\
\hline Subíndices & Temas & Subtemas & Indicadores \\
\hline \multirow{13}{*}{$\begin{array}{l}\text { 1. Responsabilidad } \\
\text { Social }\end{array}$} & \multirow{12}{*}{$\begin{array}{l}\text { 1. Responsabilidad } \\
\text { hacia el Interior }\end{array}$} & \multirow{2}{*}{$\begin{array}{l}\text { 1. Gobernanza y } \\
\text { Ética }\end{array}$} & Código de conducta \\
\hline & & & $\begin{array}{l}\text { Gobierno de la } \\
\text { organización }\end{array}$ \\
\hline & & \multirow{10}{*}{$\begin{array}{l}\text { 2. Prácticas de } \\
\text { trabajo }\end{array}$} & Relaciones laborales \\
\hline & & & $\begin{array}{l}\text { Trabajo forzoso y } \\
\text { voluntario }\end{array}$ \\
\hline & & & Seguridad y salud \\
\hline & & & $\begin{array}{c}\text { Libertad de } \\
\text { asociación y derecho } \\
\text { a la negociación } \\
\text { colectiva }\end{array}$ \\
\hline & & & $\begin{array}{c}\text { Promoción de la } \\
\text { diversidad y equidad }\end{array}$ \\
\hline & & & $\begin{array}{c}\text { Medidas } \\
\text { disciplinarias }\end{array}$ \\
\hline & & & Horario de trabajo \\
\hline & & & $\begin{array}{l}\text { Remuneración, } \\
\text { compensación y } \\
\text { beneficios }\end{array}$ \\
\hline & & & $\begin{array}{c}\text { Compromiso con el } \\
\text { desarrollo } \\
\text { profesional }\end{array}$ \\
\hline & & & $\begin{array}{c}\text { Política de despidos } \\
\text { y jubilaciones }\end{array}$ \\
\hline & $\begin{array}{l}\text { 2. Responsabilidad } \\
\text { hacia el Interior }\end{array}$ & $\begin{array}{l}\text { 1. Participación en } \\
\text { iniciativas de } \\
\text { RS/Sustentabilidad }\end{array}$ & $\begin{array}{l}\text { Compromiso y } \\
\text { participación en } \\
\text { iniciativas de } \\
\text { RS/Sustentabilidad }\end{array}$ \\
\hline
\end{tabular}




\begin{tabular}{|c|c|c|c|}
\hline & & & $\begin{array}{l}\text { Sistema de gestión } \\
\text { de proveedores }\end{array}$ \\
\hline & & \multirow[t]{3}{*}{$\begin{array}{l}\text { 2. Impacto en los } \\
\text { derechos humanos } \\
\text { de la comunidad }\end{array}$} & $\begin{array}{l}\text { Monitoreo de los } \\
\text { impactos de los } \\
\text { derechos humanos }\end{array}$ \\
\hline & & & $\begin{array}{c}\text { El trabajo infantil en } \\
\text { la cadena de } \\
\text { suministros }\end{array}$ \\
\hline & & & $\begin{array}{l}\text { Trabajo forzoso en la } \\
\text { cadena de suministro }\end{array}$ \\
\hline & & \multirow[t]{2}{*}{$\begin{array}{l}\text { 3. Participación en } \\
\text { la comunidad }\end{array}$} & $\begin{array}{c}\text { Gestión de los } \\
\text { impactos de la } \\
\text { empresa en la } \\
\text { comunidad }\end{array}$ \\
\hline & & & $\begin{array}{c}\text { Compromiso con el } \\
\text { desarrollo } \\
\text { comunitario y } \\
\text { gestión de acción } \\
\text { social }\end{array}$ \\
\hline & & \multirow[t]{3}{*}{$\begin{array}{l}\text { 4. Vinculación } \\
\text { social }\end{array}$} & $\begin{array}{c}\text { Participación de los } \\
\text { interesados }\end{array}$ \\
\hline & & & $\begin{array}{c}\text { Informes de } \\
\text { sustentabilidad }\end{array}$ \\
\hline & & & $\begin{array}{l}\text { Participación en el } \\
\text { desarrollo de } \\
\text { políticas públicas }\end{array}$ \\
\hline \multicolumn{4}{|c|}{ Subtotal: 25 ptos } \\
\hline \multirow[t]{5}{*}{$\begin{array}{l}\text { 2. Responsabilidad } \\
\text { ambiental }\end{array}$} & \multirow[t]{5}{*}{$\begin{array}{l}\text { 1. Impacto de las } \\
\text { actividades de la } \\
\text { gestión }\end{array}$} & $\begin{array}{l}\text { 1. Cambio } \\
\text { climático }\end{array}$ & $\begin{array}{c}\text { Gobierno de } \\
\text { actividades } \\
\text { relacionadas con el } \\
\text { cambio climático }\end{array}$ \\
\hline & & & $\begin{array}{c}\text { Adaptación al } \\
\text { cambio climático }\end{array}$ \\
\hline & & $\begin{array}{l}\text { 2. Gestión y } \\
\text { monitoreo de los } \\
\text { impactos sobre la } \\
\text { biodiversidad y } \\
\text { servicios de los } \\
\text { ecosistemas }\end{array}$ & $\begin{array}{c}\text { Sistemas de gestión } \\
\text { ambiental }\end{array}$ \\
\hline & & & $\begin{array}{l}\text { Prevención de la } \\
\text { contaminación }\end{array}$ \\
\hline & & & $\begin{array}{l}\text { Uso sostenible de los } \\
\text { recursos materiales }\end{array}$ \\
\hline
\end{tabular}




\begin{tabular}{|c|c|c|c|}
\hline & & & $\begin{array}{c}\text { Uso sostenible de los } \\
\text { recursos: agua y } \\
\text { energía }\end{array}$ \\
\hline & & & $\begin{array}{l}\text { Uso sostenible de la } \\
\text { biodiversidad y } \\
\text { restauración del } \\
\text { hábitat natural }\end{array}$ \\
\hline & & & $\begin{array}{c}\text { Educación y } \\
\text { conciencia ambiental }\end{array}$ \\
\hline & $\begin{array}{l}\text { 2. Impacto de las } \\
\text { actividades de } \\
\text { comercialización }\end{array}$ & $\begin{array}{l}\text { 1. Impactos } \\
\text { causados por el } \\
\text { suministro }\end{array}$ & $\begin{array}{c}\text { Impactos de } \\
\text { transporte, logística y } \\
\text { distribución }\end{array}$ \\
\hline & & & Logística inversa \\
\hline & Subtota & ptos. & \\
\hline $\begin{array}{l}\text { 3. Responsabilidad } \\
\text { Comercial }\end{array}$ & $\begin{array}{l}\text { 1. Impacto en el } \\
\text { consumidor }\end{array}$ & $\begin{array}{l}\text { 1. Beneficios para } \\
\text { la audiencia }\end{array}$ & $\begin{array}{l}\text { Necesidades } \\
\text { atendidas }\end{array}$ \\
\hline & & & $\begin{array}{c}\text { Impacto sobre la } \\
\text { salud/seguridad del } \\
\text { consumidor } \\
\end{array}$ \\
\hline & & $\begin{array}{l}\text { 2. Impacto en la } \\
\text { conducta de }\end{array}$ & $\begin{array}{c}\text { Conductas incentivos } \\
\text { y consecuencias }\end{array}$ \\
\hline & & $\begin{array}{l}\text { clientes y } \\
\text { consumidores }\end{array}$ & $\begin{array}{c}\text { Determinantes y } \\
\text { contexto de las } \\
\text { conductas }\end{array}$ \\
\hline & 2. Impacto y ética & 1. Oferta & Precio \\
\hline & comercial & comercial & Servicio \\
\hline & & & $\begin{array}{l}\text { Sistemas de } \\
\text { distribución }\end{array}$ \\
\hline & & & $\begin{array}{c}\text { Comunicación } \\
\text { responsable }\end{array}$ \\
\hline & Subtota & ptos. & \\
\hline $\begin{array}{l}\text { 4. Responsabilidad } \\
\text { legal }\end{array}$ & 1. Gestión fiscal & $\begin{array}{l}\text { 1. Contribuciones } \\
\text { federales, estatales } \\
\text { y municipales }\end{array}$ & $\begin{array}{l}\text { Participación en la } \\
\text { elaboración, } \\
\text { ejecución y } \\
\text { perfeccionamiento de } \\
\text { software fiscales }\end{array}$ \\
\hline & & $\begin{array}{c}\text { 2. Gestión } \\
\text { participativa de los } \\
\text { trabajadores }\end{array}$ & $\begin{array}{c}\text { Capacitación de los } \\
\text { trabajadores en } \\
\text { materia fiscal }\end{array}$ \\
\hline & & & $\begin{array}{c}\text { Desempeño } \\
\text { intelectual }\end{array}$ \\
\hline & & & Comité interno \\
\hline & & & $\begin{array}{c}\text { Información de la } \\
\text { gestión }\end{array}$ \\
\hline
\end{tabular}




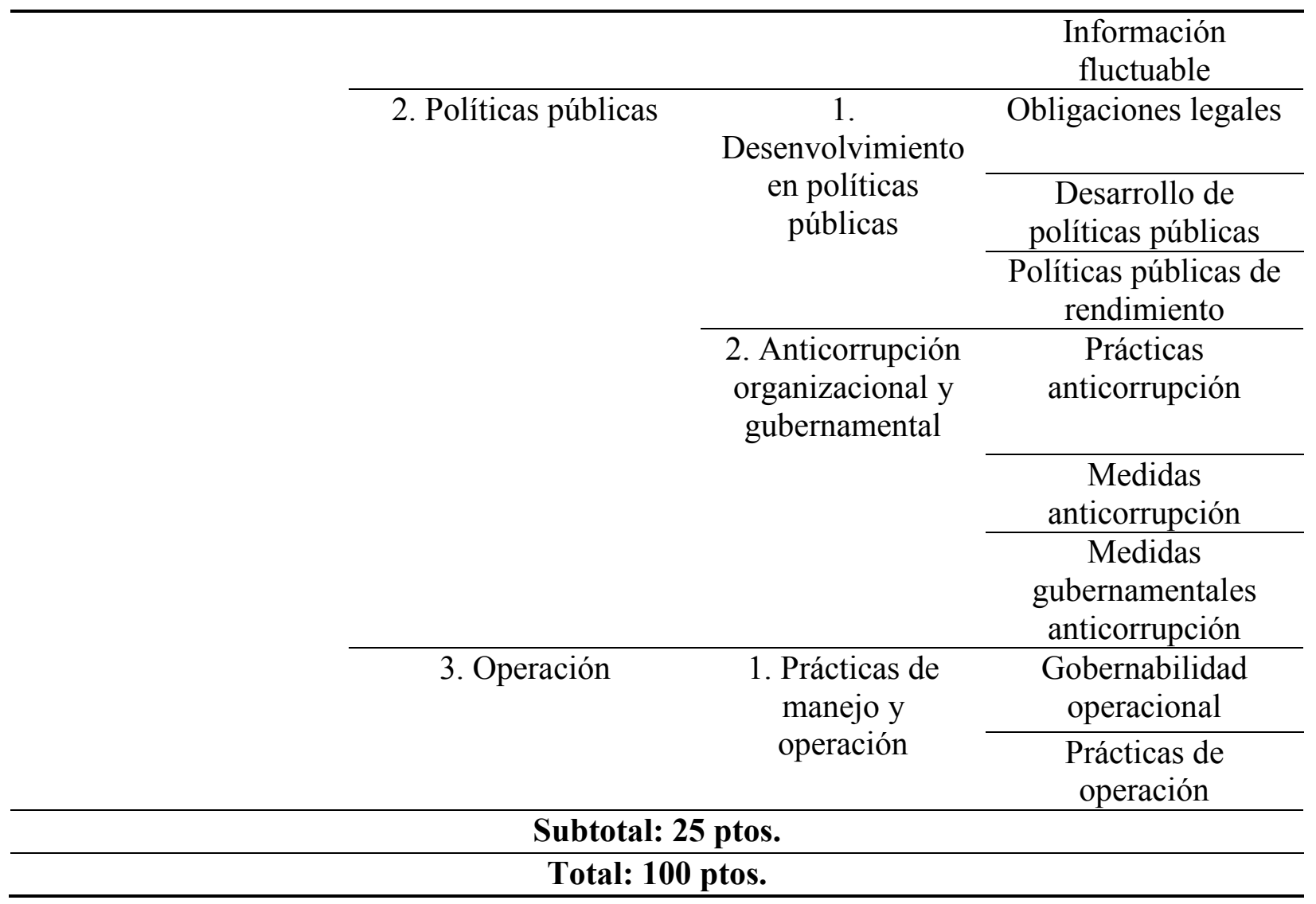

Fuente: (Guzmán, Gutiérrez, \& Castro, 2014).

El cuestionario mencionado fue aplicado a las 4 empresas procesadoras de lácteos existentes en el cantón Cañar, mencionándose a continuación:

- Empresa Comercializadora "Lácteos Dalilac Cia. Ltda". Se dedica a elaboración de leche fresca líquida, crema de leche líquida, bebidas a base de leche, yogurt, incluso caseína o lactosa, pasteurizada, esterilizada, homogeneizada y/o tratada a altas temperaturas.

- "Leo Lact". Es una empresa que cuenta con más de 10 años de experiencia en la producción y comercialización de productos y derivados lácteos, sus productos se caracterizan por su calidad y pureza. Cuentan con una gran variedad de productos con los que buscan llegar a todos hogares ecuatorianos ofreciendo productos, frescos, deliciosos y nutritivos.

- Fábrica de Lácteos "Mayrita". Es una microempresa de estructura familiar, ubicada en el Cantón El Tambo, Provincia del Cañar. Esta microempresa cuenta con dos productos: la leche cruda y el queso fresco artesanal. 
- Empresa “Lácteos Coyoctor Cia.Ltda". Cuenta con más de 10 años de experiencia y se dedica a elaboración de leche fresca líquida, crema de leche líquida, bebidas a base de leche, yogurt, incluso caseína o lactosa, pasteurizada, esterilizada, homogeneizada y/o tratada a altas temperaturas.

El proceso de recopilación de información se realizó de forma separada. Se aplicó, por un lado, el cuestionario a los trabajadores de cada una de las PYMES y por otra parte, a los directivos de las mismas con el objetivo de procurar que la información resultante fuese con la mayor transparencia posible sin ningún tipo de coacción.

El cuestionario constó de 24 preguntas, enmarcado en los siete temas mencionados anteriormente. Cada pregunta fue contestada con un SI o NO; se procedió verificar las calificaciones por cada uno de los ámbitos en las respectivas empresas, para posteriormente obtener un consolidado de las PYMES procesadoras de lácteos. En consideración, de dicha información, se obtuvo el diagnóstico de RSE de las organizaciones sujetos a este estudio.

Tabla 2.

Cuestionario según dictamen de Ethos aplicado a las empresas lácteas de Cantón Cañar

\begin{tabular}{|c|c|}
\hline Temas & Indicadores \\
\hline \multirow{5}{*}{$\begin{array}{l}\text { 1. Valores, transparencia y } \\
\text { gobierno corporativo }\end{array}$} & Compromisos éticos \\
\hline & Cultura organizacional \\
\hline & Gobierno corporativo \\
\hline & Relaciones con la competencia \\
\hline & Balance social \\
\hline \multirow[t]{3}{*}{ 2. Proveedores } & $\begin{array}{l}\text { Criterios de selección y evaluación de } \\
\text { proveedores }\end{array}$ \\
\hline & $\begin{array}{l}\text { Trabajo infantil en la cadena de } \\
\text { proveedores }\end{array}$ \\
\hline & Relaciones en las cadenas de proveedores \\
\hline \multirow[t]{9}{*}{ 3. Público Interno } & Salud, Seguridad y condiciones laborales \\
\hline & Valoración de la diversidad \\
\hline & Compromiso con el desarrollo profesional \\
\hline & Gestión participativa \\
\hline & Política de remuneración y beneficios \\
\hline & - Compromiso con el desarrollo infantil \\
\hline & Clima Laboral \\
\hline & Compromiso con el futuro de los niños \\
\hline & Comportamiento en los despidos \\
\hline
\end{tabular}




\begin{tabular}{|c|c|}
\hline & Plan de retiro \\
\hline & Relaciones con colaboradores tercerizados \\
\hline \multirow[t]{5}{*}{ 4. Medioambiente } & $\begin{array}{l}\text { El medioambiente como compromiso } \\
\text { empresarial }\end{array}$ \\
\hline & Prácticas de cuidado del Medio Ambiente \\
\hline & Impacto Medioambiental \\
\hline & Sustentabilidad de la Economía Forestal \\
\hline & Minimización de residuos \\
\hline \multirow[t]{4}{*}{ 5. Clientes/Consumidores } & Consideración de la opinión del cliente \\
\hline & Proceso de Reclamaciones \\
\hline & Marketing y comunicación \\
\hline & $\begin{array}{l}\text { Conocimiento y gerenciamiento de los } \\
\text { daños potenciales de los productos y } \\
\text { servicios }\end{array}$ \\
\hline \multirow[t]{4}{*}{ 6. Comunidad } & Política de Apoyo a la Comunidad \\
\hline & Voluntariado y participación \\
\hline & Financiamiento de Acciones sociales \\
\hline & Relaciones con organizaciones locales \\
\hline \multirow[t]{5}{*}{ 7. Gobiernos y Sociedad } & Participación Política \\
\hline & Contribución para Campañas Políticas \\
\hline & Prácticas anticorrupción \\
\hline & $\begin{array}{l}\text { Participación en proyectos sociales } \\
\text { gubernamentales }\end{array}$ \\
\hline & Construcción de la ciudadanía \\
\hline
\end{tabular}

Fuente: Elaboración Propia

\section{Resultados}

\section{Nivel Gerencial.}

- Los gerentes de las empresas, están comprometidos y ponen en práctica los valores, transparencia y gobierno corporativo, de sus respectivas organizaciones.

- El $100 \%$ de los gerentes contestó que la empresa si posee políticas y/o procedimientos de control y sanción ante posibles situaciones de acoso ya sea sexual o de otra índole.

- El 100\% de los gerentes respondieron que las empresas, si cumplen con la normativa del IESS. De igual manera respondieron que si editan anualmente memorias sobre actividades de su Responsabilidad Social Empresarial. E1 80\% manifiesta que si existe evidencia documentada sobre lo declarado y el $20 \%$ contestaron que no existe. 
- El 100\% de los gerentes contestó que, si existen principios éticos y de conducta en la relación con la competencia, además, la empresa si dispone de políticas de no utilización de productos o servicios defectuosos.

- El 100\% de los gerentes expresan que la empresa si dispone de un balance social, de las acciones sociales y ambientales de la empresa; el 60\% respondió que si realiza auditorías externas de la situación financiera y el 40\% que no la realiza. El 40\% respondió que la empresa si publica en la web aspectos económicos y financieros, ambientales de sus actividades y el $60 \%$ que no los publica.

- El 100\% de los gerentes respondieron que la empresa si se interesa por sus principios, políticas, responsabilidad social y cumplimiento de la normativa laboral, del IESS y fiscal. El 60\% contestó, que la empresa si dispone de una política determinada de Responsabilidad Social en relación con los proveedores y el $40 \%$ de las empresas no disponen.

- El 100\% de los gerentes respondieron que la empresa orienta a sus proveedores a cumplir con sus principios de responsabilidad social empresarial y colabora con ellos en su implementación y disponen de un plan de satisfacción con los proveedores.

- El 100\%, respondieron que si consideran entre sus proveedores a personas de la comunidad, asociación y pequeños productores, iniciativas solidarias u otro tipo de asociaciones y si negocian con transparencia y establecen relaciones contractuales solo en base a criterios de utilidad.

- El 100\% de los gerentes respondieron que si desarrollan en la empresa actividades sociales con la participación de trabajadores y sus familias. El 80\% de los gerentes respondieron que si se realizan evaluaciones de desempeño a los directivos por parte de sus subordinados y el $20 \%$ respondieron que no realizan evaluaciones. El 100\% de los gerentes respondieron que la empresa si considera la situación social del trabajador al momento de despido.

- El $100 \%$ de los gerentes respondieron que la empresa que, si capacitan al personal sobre el tema del medio ambiente y su preservación, además si consideran aspectos ambientales al seleccionar proveedores, si practican el reciclado de insumos y otros productos tóxicos, si promocionan la 
reducción del consumo del agua y energía eléctrica y si disponen de un control del impacto ambiental que genera sus actividades y comunica a sus clientes.

- El 100\% de los gerentes respondieron que la empresa si dispone de un control del impacto ambiental, genera sus actividades y comunica a sus clientes y llevan una política de atención de quejas o denuncias sobre sobre la contaminación del medio ambiente.

- El $100 \%$ de los gerentes respondieron que la información brindada al público si es transparente, respecto a los posibles riesgos de los productos o servicios que la empresa ofrece, si están especificados los precios y condiciones de comercialización acorde al producto o servicio que se ofrece, si disponen de un programa orientado a la salud y seguridad del cliente por sus productos o servicios y si se preocupan de no utilizar productos y servicios prohibidos en otros países.

- El 100\% de los gerentes respondieron que la empresa si cuenta con políticas de apoyo a la comunidad y es de conocimiento de sus trabajadores. El 60\% respondieron que si colaboran cuando se requieran mejoras en los equipamientos públicos del entorno, como escuelas, puestos de salud, áreas verdes, etc. El 40\% respondieron que no colaboran con la comunidad. El 100\% de los gerentes respondieron que si participan activamente en discusiones sobre los problemas comunitarios y de búsqueda de soluciones y que la empresa si mejora los impactos de la misma en la comunidad próxima a su entorno.

- El 100\% de los gerentes respondieron que la empresa si genera oportunidades para que los trabajadores y directivos desarrollen actividades de apoyo comunitario. El 80\% respondieron que la empresa si comunica al personal sobre las actividades de apoyo comunitario en la que participa y el $20 \%$ respondieron que no se comunica al personal.

- El 100\% de los gerentes respondieron que la empresa si destina recursos para programas de apoyo comunitario y si se evalúan los resultados de los apoyos destinados al desarrollo comunitario. El $40 \%$ respondieron que la empresa apoya a varias entidades con donaciones, financiamiento e implementación de proyectos divulgando experiencias exitosas y el $60 \%$ respondieron que no lo hacen.

Nivel de Trabajadores. 
- El 100\% de los empleados de las empresas respondieron que la empresa si tiene divulgada (interna y externa) su misión y visión. El 85\% respondieron que la misión y visión si incluyen consideraciones sobre la responsabilidad social empresarial y el 15\% no incluye. El 70\% respondió que en la redacción de la misión y visión si participan distintos estamentos de la empresa y el 30\% respondió que no participan. El 55\% respondió que en la visión y la visión de la empresa son revisadas periódicamente y el 45\% respondió que no la revisan periódicamente. El 75\% respondieron que el código de ética o conducta si considera a las partes interesadas, y el $25 \%$ respondió que no las considera. El 85\% respondieron que en la etapa de selección y reclutamiento si mencionan aspectos éticos y el $15 \%$ no la hacen.

- El 75\% de los empleados contestó que la empresa si promociona y practica valores y el código de ética con regularidad y el 25\% respondió que no lo hace. El $15 \%$ si realiza evaluaciones al personal y el $85 \%$ no las realiza. El $80 \%$ de las empresas encuestadas si han cancelado o cancelarían contratos con proveedores por conductas no éticas y el 20\% no lo han cancelado. El $85 \%$ de los empleados respondieron que la empresa si posee políticas y/o procedimientos de control sanción ante posibles prácticas corruptas y el $15 \%$ respondió no posee políticas y/o procedimientos de control sanción. El 80\% respondió que, si existe una política de informar a los superiores sobre toda comisión, obsequio, etc. Recibido por parte de terceros y el 20\% respondió que no.

- El 100\% de los empleados respondieron que la empresa si cumple con la normativa del IESS. El $57 \%$ respondieron que si edita anualmente memorias sobre actividades de su Responsabilidad Social Empresaria y el 43\% respondió que no lo hace. El 85\% contesto que si existe evidencia documentada sobre lo manifestado y el $15 \%$ de los gerentes contesto que no existe.

- El 80\% de los empleados contestó que la empresa si dispone de un balance social, acciones sociales y ambientales de la empresa y el 20\% dijo que no dispone. El 70\% respondió que si realiza auditorías externas de la situación financiera de la empresa y el 30\% que no la realiza. El $65 \%$ respondió que la empresa si publica en la web aspectos económicos y financieros, ambientales de las actividades de la empresa y el 35\% que no pública.

- El 91\% de los empleados respondieron que la empresa si se interesa por sus principios, políticas, responsabilidad social y cumplimiento de la normativa laboral, del IESS y fiscal y el 9\% dijo que no. El $80 \%$ contestó que la empresa si dispone de una política determinada de responsabilidad 
social en relación con los proveedores y el $20 \%$ de las empresas no disponen una política de responsabilidad social en relación con los proveedores.

- El 75\% de los empleados respondieron que la empresa si orienta a sus proveedores a cumplir con sus principios de responsabilidad social empresarial y colabora con ellos en su implementación y el 25\% respondió que no lo hace. El 61\% de los empleados indican que la empresa si dispone de un plan de satisfacción con proveedores y 39\% respondió que no dispone plan de satisfacción con proveedores. El 70\% expresó que si consideran entre sus proveedores a personas de la comunidad, asociación y pequeños productores, iniciativas solidarias u otro tipo de asociaciones y el 30\% respondió que no consideran. El 75\% de los gerentes respondieron que la empresa si negocian con transparencia y establece relaciones contractuales solo en base a criterios de utilidad y el 25\% dijo que no.

- El 100\% de los empleados respondieron que la empresa si dispone de un plan de accidente de trabajo y enfermedades profesionales. El 57\% respondieron que la empresa considera beneficios adicionales para la salud de sus colaboradores y sus familiares y el $43 \%$ dijo que no. El 57\% respondieron que la empresa si se preocupa por mejorar las condiciones laborales a más de las establecidas por las exigencias globales y el 43\% respondió que no. El 55\% respondieron que la empresa si promociona actividades de anti estrés para sus colaboradores y el 45\% contestó que no.

- El 95\% de los empleados respondieron que si participan de la utilidad de la empresa y el 2\% dijo que no. El 75\% indicaron que la empresa si incentiva el desempeño del trabajador y el $25 \%$ respondió que no. El 80\% expreso que si dispone la empresa de un manual de cargos funciones y salarios y el $20 \%$ respondió que no.

- El 70\% de los empleados respondieron que si desarrollan en la empresa actividades sociales con la participación de trabajadores y sus familias y 30\% dijo que no. El 57\% respondieron que la empresa si desarrolla actividades sociales con la participación de trabajadores y sus familias y el $43 \%$ respondió que no. El 80\% respondieron que si se realiza evaluaciones de desempeño a los directivos por parte de sus subordinados y el 20\% respondieron que no realizan evaluaciones. El 55\% de los empleados respondieron que la empresa si considera la situación social del trabajador al momento de despido y el 45\% respondió que no. El 45\% respondieron que la empresa si dispone de un plan de rotación de personal, y el 55\% respondieron que no dispone de un plan de rotación de personal. 
- El 85\% de los empleados respondieron que la empresa si capacita al personal sobre el tema de medio ambiente y su preservación y el 15\% dijo que no. El 65\% respondieron que la empresa si considera aspectos ambientales al seleccionar proveedores y el 35\% dijo que no. El 85\% respondieron que la empresa si practica el reciclado de insumos y otros productos tóxicos y el 15\% dijo que no. El 70\% respondieron que la empresa si promociona la reducción del consumo del agua y energía eléctrica y el 30\% contesto que no. El 85\% respondieron que la empresa si dispone de un control del impacto ambiental que genera sus actividades y comunica a sus clientes y el 15\% respondió que no. El 80\% de los gerentes respondieron que la empresa si dispone de un control del impacto ambiental que genera sus actividades y comunica a sus clientes el 20\% dijo que no. El $65 \%$ de los gerentes respondieron que la empresa si dispone de una política de atención de quejas o denuncias sobre sobre la contaminación del medio ambiente y el 35\% dijo que no.

- El 100\% de los empleados respondieron que la información brindada al público si es transparente, respecto a los posibles riesgos de los productos o servicios que la empresa ofrece. El 95\% respondieron que si están especificados los precios y condiciones de comercialización acorde al producto o servicio que se ofrece y el 5\% dijo que no. El 91\% respondieron que si dispone de un programa orientado a la salud y seguridad del cliente por sus productos o servicios y 9\% contestó que no. El 75\% respondieron que la empresa si se preocupa de no utilizar productos y servicios prohibidos en otros países y $25 \%$ contestó que no.

- El 91\% de los empleados respondieron que la empresa si cuenta con políticas de apoyo a la comunidad y es de conocimiento de sus trabajadores y el $9 \%$ contestó que no cuenta con políticas de apoyo a la comunidad. El 87\% respondieron que si colabora cuando se requiera con mejoras en los equipamientos públicos del entorno, como escuelas, puestos de salud, áreas verdes, etc. El 15\% respondieron que no colaboran con la comunidad y el 13\% dijo que no. El 87\% respondieron que si participan activamente en discusiones sobre los problemas comunitarios y de búsqueda de soluciones y 13\% contestó que no. El 85\% respondieron que la empresa si mejora los impactos de la misma en la comunidad próxima más allá de las regulaciones existentes (ruidos, olores; movimientos de vehículos, etc.) y el 15\% contestó que no.

- El $87 \%$ de los empleados respondieron que la empresa si genera oportunidades para que los trabajadores y directivos desarrollen actividades de apoyo comunitario 13\% contestó que no. El 
$85 \%$ respondieron que la empresa si comunica al personal sobre las actividades de apoyo comunitario en la que participa y el $15 \%$ dijo que no.

- El 85\% de los empleados respondieron que la empresa si destina recursos para programas de apoyo comunitario 15\% contestó que no. El 70\% de los empleados respondieron que si se evalúan los resultados de los apoyos destinados al desarrollo comunitario y el 30\% contestó que no. El 70\% respondieron que la empresa apoya a varias entidades con donaciones, financiamiento e implementación de proyectos divulgando experiencias exitosas y el 30\% dijo que no.

\section{Conclusiones}

Es importante que todas las empresas, independientemente de su tamaño, implementen la Responsabilidad Social Empresarial y de forma correcta, no solo pensando en su bienestar económico, sino también buscando un bienestar común que repercuta en verdaderos cambios positivos en la sociedad y así puedan combatir muchos de los problemas que hoy agobian al mundo.

La implementación de prácticas de RSE dentro de las PYMES, permite construir una estrategia integral, enfocada en sus grupos de interés mediante el reconocimiento de sus acciones, lo cual repercute positivamente en las utilidades de la empresa, la ventaja competitiva y el posicionamiento en el mercado, en búsqueda de la sostenibilidad de la misma.

Por estas razones, teniendo en cuenta que las empresas se clasifican como microempresas según la ley Mipyme, se hace indispensable conocer los resultados arrojados en este diagnóstico de prácticas de responsabilidad social, ya que permite fortalecer, mejorar y resolver las debilidades de las empresas e identificar los aspectos a mejorar, con el fin de lograr sostenibilidad y perdurabilidad en el tiempo, además de alcanzar una ventaja competitiva presente en toda la cadena de valor.

\section{Recomendaciones}

- Con el propósito de fortalecer, mejorar y resolver las debilidades encontradas dentro del diagnóstico de las prácticas de RSE al interior de las empresas, se recomienda iniciar el proceso de mejoramiento de los aspectos éticos. 
- Incluir dentro de la misión y visión aspectos sobre la responsabilidad social, como también tomar en consideración la participación de distintos estamentos de la empresa al momento de la redacción e involucrar a los empleados para que validen entre todos los códigos de ética o conducta formal, así como también considerar a los stakeholders y dar a conocer aspectos éticos en la etapa de reclutamiento.

- Promocionar y practicar valores y el código de ética, así como también realizar evaluaciones al personal. Gobierno corporativo: Se recomienda tener evidenciado todas las ayudas a las comunidades, medioambiente, entre otros.

- Comunicar la empresa a sus empleados sobre las actividades de apoyo comunitario en la que participa Gobiernos y Sociedad: Construcción de la ciudadanía: Realizar actividades como: cívicas, abordando derechos y deberes.

- Considerar aspectos ambientales al momento de seleccionar proveedores, así como reducir desperdicios tóxicos y el consumo de energía eléctrica y el agua.

\section{Referencias Bibliográficas}

\section{Acosta González, B. V. (s.f.).}

Araque, W. (2015). Caracterizacion de la pyme ecuatoriana. Revistagestion, 64-67.

Guzmán, L., Gutiérrez, L., \& Castro, L. (2014). DICTAMEN DEL ETHOS: AVANCES HACIA UNA PROPUESTA.

Hernàndez, J. (2013). La responsabilidad social corporativa y el desarrollo local: una aproximación en tiempos de crisis. Prisma Social: revista de investigación social, 119-156.

Raufflet, E., Lozano, J., Barrera, E., \& García de la Torre, C. (2011). Responsabilidad social empresarial. Mexico D.F: Pearson.

Rodríguez de Ramírez, M. D. (2013). Informes de sostenibilidad.

Torres, W. (19 de 05 de 2014). DerechoEcuador. Obtenido de https://derechoecuador.com/resposabilidad-social-empresarial-iso-26000 
Diagnóstico de responsabilidad social empresarial de las pymes procesadoras de lácteo, en el Cantón Cañar

Viola, M., \& Sepliarsky, P. (2012). Indicadores de Responsabilidad Social Empresaria-Análisis y factibilidad de aplicación- "Caso San Lorenzo".

Viteri, G. (2010). Plataforma de Responsabilidad Social. Boletin Informativo $N^{\circ}$ 1. SOCIEDAD CIVIL EN RESPONSABILIDAD SOCIAL. 